\title{
The existence of personites
}

\author{
Matti Eklund $^{1}$ (D)
}

Published online: 8 May 2019

(C) The Author(s) 2019

\begin{abstract}
Mark Johnston and Eric Olson have both pressed what Johnston has dubbed the personite problem. Personites, if they exist, are person-like entities whose lives extend over a continuous proper part of a person's life. They are so person-like that they seem to have moral status if persons do. But this threatens to wreak havoc with ordinary moral thinking. For example, simple decisions to suffer some short-term hardship for long-term benefits become problematic. And ordinary punishment is always also punishment of the innocent, since it punishes personites that didn't exist when the crime was committed. An initially attractive way around the personite problem may be to simply deny that personites exist. But as I discuss in this talk, relating to contemporary discussions in metaontology (the doctrine of quantifier variance, and Ted Sider's ontological realism), this response for principled reasons doesn't work. The problems I discuss illustrate the significance of metaontological considerations for issues in ethics and metaethics, and generalize widely beyond the personite problem.
\end{abstract}

Keywords Personites · Metaontology · Ontological realism · Quantifier variance · Metaethics

\section{Introduction}

The following claim might seem perfectly obvious: Some putative entities, the Fs, have moral status only if they exist. If Fs don't exist, then Fs don't have interests that need to be taken into account. In this paper, I cast doubt on this claim, in the first instance through raising questions about the talk of existence. I discuss the

Matti Eklund

matti.eklund@filosofi.uu.se

1 Uppsala University, Uppsala, Sweden 
consequences various metaontological views have for the role of existence considerations in moral theorizing. While my target is the general claim stated, the discussion will be centered on the personite problem, introduced by Johnston (2016a, b) and Olson (2010).

\section{The personite problem}

Johnston and Olson are both concerned with the problem posed for ethical thinking by what Johnston calls personites (and Olson calls subpeople): "shorter-lived very person-like things that extend across part, but not the whole, of a person's life". ${ }^{1}$

Of course, it is not uncontroversial, or even particularly intuitive, that there are such things as personites. Some may be inclined to get around the problem I will describe by simply denying that personites exist. But there are prominent ontological views given which personites do exist. Suppose for example that a standard four-dimensionalist view is true: persisting objects are sums of their temporal parts and for every collection of temporal parts there is an object which is their sum. Then a personite is an object that is the sum of a (temporally continuous ${ }^{2}$ ) proper subset of a person's temporal parts. A three-dimensionalist view too is compatible with the existence of personites. For the three-dimensionalist personites coincide with persons for proper parts of the person's lives. In general, personites exist given generous ontologies, ones given which putative entities meeting already rather minimal conditions do exist. ${ }^{3}$

Personites, if they exist, appear to present a deep problem for our moral thinking. I will refer to this problem as the personite problem. If persons have moral status then personites do too, given their similarity to persons-and this leads to problems. First, if personites have moral status then something as seemingly unproblematic as sacrificing happiness in the short term for benefits in the long term, like when one works really hard to achieve some goal and the work itself brings no intrinsic reward, becomes morally problematic: for the personites who go out of existence before the goal is reached are made to suffer for something that is of no benefit to them. Second, consider punishment for some misdeed. Personites which did not exist at the time of the misdeed, and hence did not commit the misdeed, are among the entities punished. Third, relatedly, consider reward for some good deed. Personites which did not exist at the time of the good deed, and hence did not perform it, are among the entities rewarded.

Johnston concludes that the existence of personites has "surprising, repellent, and perhaps even disastrous consequences for our ordinary moral outlook”. ${ }^{4} \mathrm{He}$ says,

\footnotetext{
1 Johnston (2016a, p. 617).

2 Some temporally discontinuous entities might certainly raise the same problems as personites do; but for simplicity let us focus on personites as characterized in the text.

3 I borrow the label "generous" from the title of Olson's paper, "Ethics and the Generous Ontology".

4 Johnston (2016b, p. 206).
} 
If there are such things as personites with a moral status and therefore subject to considerations of desert, our practices of punishment and reward are hopelessly scattershot. Punishment is always collective punishment; praise and reward are almost always egregiously overdone. ${ }^{5}$

Johnston (2016a) holds that the problem arises on a "naturalistic" worldview, and speaks of the threat that naturalism is "an implacable enemy of central things human beings rightly hold dear". ${ }^{6}$ He does not spell out what he means, but the idea must be that while on a naturalist view on the world one cannot point to a relevant difference between persons and personites, the non-naturalist does allow for such differences. Olson discusses similar problems as Johnston discusses, but is more restrained, speaking only of "troubling ethical consequences". 7

It may be thought that at least certain ethical theorists-certain consequentialists-might not see the existence of personites as presenting a problem for ordinary moral thinking. Some forms of consequentialism anyway just take into account overall consequences. ${ }^{8}$ Johnston (2016a) discusses this and concludes that even the relevant kind of consequentialist should be troubled by the existence of personites. In brief, Johnston's reasoning is this. Either time is continuous or it is not. If it is continuous then there are uncountably many personites, and every time we benefit some entity we benefit uncountably many entities; and whether I benefit one person or millions of persons I benefit equally many entities. If time is not continuous, then persons who live longer are, so to speak, accompanied by more personites, and hence benefiting them is, for the consequentialist, for this very reason better than benefiting those who live shorter lives. ${ }^{9}$

Persons, but not mere personites, arguably satisfy a kind of maximality criterion. Within a four-dimensionalist framework this criterion can be stated as: persons are maximal sums of person-stages. Take whatever relation $\mathrm{R}$ is such that two personstages are stages of the same person by virtue of $\mathrm{R}$ holding between them. Then persons correspond to maximal R-chains. Someone who wishes to see a significant difference in moral status between persons and personites might be drawn to appeal to this feature: the reason that persons have a greater moral status than personites do

\footnotetext{
5 Johnston (2016b, p. 209).

6 Johnston (2016a, p. 641).

7 Olson (2010, p. 269).

8 Olson (2010, p. 265), suggests that a maximizing utilitarian could take the existence of personites in her stride.

9 A natural response is to say that the relevant kind of consequentialist should just take into account amount of (say) pleasure and pain, and the existence of personites in addition to persons does not affect the amount of pleasure and pain. The person's pleasure /pain is the personite's pleasure/pain, and vice versa. Perhaps in the end this works (my aim in this paper will just be the limited one of considering one particular response to the personite problem), but it is by no means straightforward. The question arises: when do we count pleasures and pains as identical and when do we count them as distinct? So long as it is metaphysically possible that two coincident creatures can have distinct pleasures/pains we cannot simply point to the fact that the person's pleasure/pain is colocated with the personite's pleasure/pain. And if it is maintained that it suffices for two pleasures to be distinct that they are had by different creatures, this strategy does not afford a way around the problem, for the person's pleasures would be distinct from the personite's pleasures.
} 
is that they satisfy this maximality criterion. Johnston's concern about this proposal is that maximality is "an extrinsic feature of the sum in question; it depends on what stages exist before or after the sum itself exists and just how they stand to the stages in the sum". ${ }^{10}$ But an extrinsic difference between persons and personites cannot account for there being a significant difference in moral status between persons and personites. For how can the issue of whether an entity has moral status be dependent upon goings-on outside of that entity?

There is obviously a lot that can be said about the personite problem. ${ }^{11}$ But as advertised, I will here focus on one specific type of issue. It would appear that a theorist whose ontology lets her say that there are no personites has an easy way around the problem. But matters are more complicated. I will show how some seemingly rather esoteric issues in metaontology appear to be relevant to the personite problem. The personite problem cannot in fact be easily avoided by adopting a less generous ontology. Anticipating somewhat, what I will be talking about is this. A central theme in metaontology is that there arguably are other possible existence concepts, not coextensive with the ordinary concept of existence. Even if Ks exist (/don't exist) in the sense of the ordinary concept of existence, it may be that Ks don't exist (/exist) in the sense of some other existence concept. These concepts may then be compared with each other: some existence concept may be more fundamental than, or metaphysically privileged over, the others. And the issue arises: in what sense of "exists" do personites not exist?

Metaontology turns out to be relevant to ethics in an unanticipated way. Although, as we shall see, matters are more complicated, and the issue turns out to be more general, and affects metaissues going beyond metaontology.

Accordingly, my main aim is not to address the personite problem itself head-on, but to discuss some ways in which issues in metaontology - and beyond-relate to issues in ethics. While I focus on the personite problem, there is a general point. It might seem obvious that whether some entities count in ethical deliberation turns on whether they exist or not. Purported entities count only if they exist. The present discussion problematizes this. The discussion displays the relevance of metaontology, and other meta-discussions, for issues in ethics.

I will discuss two different suggestions regarding ontology that may be held to serve to get around the personite problem. The main suggestion I will discuss is the obvious suggestion, already brought up, that while persons exist, personites simply don't. Personites don't have moral status (and they don't feel pain, don't have

\footnotetext{
10 Johnston (2016b, p. 199).

11 One reply I have regularly encountered in discussion is that if one focuses on consent and preferences, then the problem goes away. The idea is that the personites accompanying you always consent to whatever you do and have the same preferences as you have, and hence they, e.g., consent to your shortterm sacrifices for long term benefits - so such sacrifices are in fact not problematic even if there are personites. There is much to say about this but here are two remarks. First, this does not get around the problems regarding punishment and reward. Second (since there anyway are difficult questions to be asked about the morality of reward and punishment) what about when the benefits come first and the sacrifice later? E.g. you do decide to live hard when you're young, full well knowing this will bring ailments when you're older. Then consider the personites which come into existence only after the rewards have been reaped, and only suffer the ailments. They did not consent to anything.
} 
interests,...) since they don't exist. Call this the existence reply. ${ }^{12}$ But I will also discuss the somewhat more subtle suggestion that while both persons and personites exist, persons somehow have a privileged ontological status-personites are ontologically dependent upon or less natural than persons-and this, supposedly, gets around the problem for ethics that personites seem to present. Call this the second-class reply. (Since this reply is centered on the idea that personites are second-class entities.)

Let me discuss these suggestions in reverse order, starting with the more subtle one, the second-class reply. The reason is that some lessons from the discussion of this reply are relevant to the existence reply.

\section{Dependence and privilege}

In this section, I will present and criticize the second-class reply. I will first do so by discussing how this reply comes up in Johnston.

Johnston briefly mentions the possibility that personites might be ontologically dependent on persons but not vice versa, and that this would help get around the personite problem.

If there are other enduring substances alongside us within our spatio-temporal envelopes then there might still be hope [for a solution to the problem] if those substances are ontologically dependent on us...For then, we might argue that their interests are derivative upon ours, in such a way as to make it double or multiple counting were we to count their interests alongside ours. ${ }^{13}$

There are two different ideas here. One is that if some entities with moral status spatially coincide at some time $t$ and among these entities there is one such that the others ontologically depend on it, then it is double counting to count the interests of all these entities when morally evaluating something they undergo at $t$. The other is that in such cases, where one of the entities ontologically depends on the other, it is the more fundamental entity's interests that count morally. I will focus on the second idea. There may be cause to problematize the first one as well, but I will grant the first idea for present purposes. Importantly, the first idea does not by itself get around the personite problem: for even given a ban on double counting, the question remains of whether to prioritize the interests of persons or of personites. ${ }^{14}$ That is where ontological dependence is supposed to come in. The interests of

\footnotetext{
12 I will, as advertised, problematize the existence reply. But still, another possible connection between metaontology and the personite problem is this. Some views in metaontology, like that of Thomasson (2015), are to the effect that existence is easy: roughly, for any putative entities, Ks, Ks exist so long as their doing so is compatible with the empirical facts. Friends of such views are committed to the existence of personites, and the existence reply is not available to them.

13 Johnston (2016b, p. 227).

14 Above, in footnote 9, I mentioned that a kind of consequentialist might seek to get around the problem by just appealing to the amount pleasure/pain. Already the ban on double counting, if it can be justified, might be sufficient for the purposes of this consequentialist strategy. In that footnote I mentioned some problems regarding the prohibition on double counting.
} 
persons are supposed to have priority over those of personites, for personites are ontologically dependent upon persons.

Johnston's own worry about this strategy is that he "cannot see how a purely naturalistic ontology can underwrite the idea that we are enduring substances that are...ontologically distinguished, within our spatio-temporal envelopes". ${ }^{15}$

There is also a problem which Johnston does not bring up, and I find this problem to be at least as serious - and more instructive when it comes to themes that will come up later. Even if personites really are ontologically dependent upon persons, it is a further question what this means when it comes to moral matters. Personites, while ontologically dependent, could still be such that morally, they have the same status as persons, or even morally matter more than persons do. Compare perhaps an analogy: even if pleasure and pain ontologically depend on lower-level features, it can be that what matters morally is pleasure and pain and not these features. The lower-level things are enablers of the dependent things, but it is the dependent things, the states of pain and pleasure, that are the loci of moral significance.

Compare also a point sometimes made against Derek Parfit's views on personal identity. Parfit is hospitable to the idea that metaphysical reductionism about personal identity (the existence of a person amounts to nothing over and above the obtaining of the right kind of continuity) yields that what matters for moral matters-and, relating to Parfit's specific topic, for self-concern-is not the existence of a person but the obtaining of the right kind of continuity. ${ }^{16}$ But a number of theorists have protested against Parfit's reasoning here. As Kieran Setiya puts it: "What matters in self-concern is whether I will suffer, not whether that fact can be explained in other terms". ${ }^{17}$ To put this in present terminology: it is irrelevant to the moral and prudential significance of the state of affairs that I suffer whether it is ontologically dependent on other facts. Setiya specifically focuses on what matters in self-concern but the point is general.

There is no immediate connection between some entities being dependent and their somehow thereby mattering less. Needless to say, this is compatible with the dependent entities sometimes actually mattering less. But no mere appeal to the dependence of personites upon persons can get around the personite problem.

The suggestion Johnston brought up was that one might advert to personites being ontologically dependent on persons, and (supposedly) hence of lesser moral standing. There is another possible version of the second-class reply which it might be useful to pause on. Some metaphysicians today believe in some descendant of David Lewis's notion of naturalness, and think that entities can be classified in terms of how natural or 'joint-carving' or elite-or, as I will put it, how metaphysically privileged - they are. ${ }^{18}$ This talk of privilege has also crept into metaethics. For example, different authors have held that we ought to focus on a form of moral realism according to which moral properties are metaphysically

\footnotetext{
15 Johnston (2016b, p. 227).

16 Parfit (1984, §102).

17 See, e.g., Setiya (2015, p. 450f), Whiting (1986, p. 552) and Johnston (1997, p. 167).

18 See primarily Sider (2011).
} 
privileged. ${ }^{19}$ In the case of aesthetics, Ted Sider (2011) has argued that a sensible projectivist view in aesthetics is one according to which there are different tastiness concepts and none of them picks out a property that is more privileged than all others. $^{20}$ The corresponding non-projectivist view would be one where there is a property picked out by a tastiness concept that is more privileged than other properties picked out by tastiness concepts.

One may think that even if personites too exist, persons may be more metaphysically privileged than personites, and-hence-be of greater moral importance than personites. I will argue that this suggestion, too, fails, and for reasons similar to those for which the suggestion Johnston brought up is not workable.

Even if the notion of metaphysical privilege is properly central to metaphysics, and even if this notion of metaphysical privilege is applicable to normative properties, metaphysical privilege may be the wrong sort of thing to focus on when we assess what moral status different entities have. What is metaphysically privileged in the sense gestured towards need not thereby be, so to speak, normatively privileged.

It is common to hold that metaphysical privilege is primitive, not reducible to anything else. But even so, different theorists provide different handles on how we can recognize what is privileged. Here theorists often appeal to explanatoriness. What is metaphysically privileged is what is genuinely, in and of itself explanatory. $^{21}$

I will first illustrate the point that metaphysical privilege need not go hand in hand with normative privilege by considering a different normative concept, the concept of being right. After that I will return to the issue of person-like entities.

Suppose now that two different groups of people use different, non-coextensive rightness concepts, R1 and R2, to guide their actions. When calling R1 and R2 rightness concepts, I here mean that their practical use is like that of our concept RIGHT: considerations regarding what is $\mathrm{R} 1$ and $\mathrm{R} 2$, respectively, serve to guide action in the way that considerations regarding what is right guides action for us. Suppose further that the property, P1, that R1 picks out is more explanatory than the one R2 picks out, P2. Does that mean that the group using R1 somehow guide their actions in a better way than does the group R2? Hardly. What does the general explanatoriness of a property have to do with the appropriateness of using considerations about the instantiation of this property for a specific action-guiding purpose? Suppose for example that P1 is more explanatory because it figures in explanatory psychological laws: it helps explain things regarding how persons

\footnotetext{
19 See, e.g., Dougherty (2014), Dunaway (2016), Dunaway and McPherson (2016), Schoenfield (2016) and Wasserman (2012).

20 Sider (2011, pp. 57ff).

21 See, e.g., Sider (2011, ch. 3), and Dunaway and McPherson (2016). In principle, this conception of metaphysical privilege can allow that higher-level (ontologically dependent) features are metaphysically privileged over lower-level ones. For example, it could be that multiply realizable mental properties can be more explanatory than, and more metaphysically privileged than, their physical realizers.
} 
behave. That does not mean that P1 is more relevant when it comes to guiding actions in the manner that considerations about what is right guide action. ${ }^{22}$

Turn now to personal identity, and suppose that there exist person-like entities corresponding to different purported criteria of personal identity-for example, that there are person-like entities corresponding to a physical or biological criterion, and that there are person-like entities corresponding to a psychological criterion. Suppose further, as does not seem far-fetched, that the former person-like entities are more natural than the latter. There is arguably a range of explanations-physical and biological explanations - such that physically or biologically individuated entities are more relevant to those explanations than psychologically individuated entities are. But it would seem misguided to use this fact as part of an argument that psychologically individuated entities have a lesser moral status than physically individuated entities do. And indeed, given that psychological features, like anticipation, memory connections and continuity in personality traits, arguably are more relevant to issues of self-concern, responsibility and desert, there are independent considerations in favor of suspecting that psychologically individuated entities have a higher moral status, if these different person-like entities can differ in moral status at all. Note: I am not claiming either that physically individuated entities are more natural or that psychologically individuated entities have a higher moral status; all I am saying is that even though it may be reasonable to suppose the former to be the case, that does not have any immediate bearing on the normative issues with which we are presently concerned. ${ }^{23}$

Perhaps if considerations about the instantiation of a property are appropriately used for some action-guiding purpose, that means that the property is in some sense explanatory in some specific respect: the presence or absence of the property is relevant to whether some action should be performed, and arguably explains why the action should be performed, in case it should be. So maybe if P2 is more appropriately action-guiding, then it is in that respect more explanatory. A certain action ought to be performed because it has P2. But even if this indeed can be regarded as some local kind of explanatoriness, it is not guaranteed to line up with the general explanatoriness of the property. (What if in response to this kind of consideration the friend of explaining privilege in terms of explanatoriness says that it is this kind of local explanatoriness is a guide to privilege? A consequence of this view would be that some things can be privileged in one respect but not another. I will not explore this view in any detail. But one problem with this idea, relevant in the context, is that the claim that persons are metaphysically privileged over personites in the relevant respect just amounts to the claim that the moral status of persons is somehow higher than that of personites.)

\footnotetext{
22 See Eklund (2017), especially chapters 1-3, for extended discussion of the possibility of alternative normative concepts, including alternative rightness concepts, and how to understand claims about normative privilege of specific rightness concepts.

23 As illustrated by the example in the text of physically versus psychologically individuated persons, the personite problem is just an instance of a broader class of problems, concerning the moral status of persons and the moral status of other broadly person-like entities.
} 
When cashing privilege talk in terms of objective explanatoriness, I have fastened on one particular way among many of getting a handle on such talk. But the point is general. Standard ways of getting a handle on talk of metaphysical privilege do not directly relate to normative matters. Facts about metaphysical privilege have no immediate relevance for normative matters.

Let me just take one more example. When introducing his notion of naturalness, Lewis prominently talked about what makes for objective similarity. But there are ways in which P1 can trump P2 when it comes to making for objective similarity without this being of normative significance. Agents or actions that have P1 may be similar for example for example in that they are similar for the purposes of psychological generalizations. But this does not mean that what has P1 is thereby morally more important.

I conclude that the second-class reply to the personite problem does not work. Turn then to the existence reply: persons exist but personites do not, and hence the problem is avoided. Surely, one may think, if personites simply don't exist then a fortiori they don't feel pain or have interests or have moral status. But there are significant complications here too. I now turn to discuss these.

\section{Existence and quantifier variance}

Let me now turn to the main thing I want to discuss: the existence reply to the personite problem. To repeat, this is the reply that personites simply don't exist and hence the personite problem goes away. And again to stress, I am using the existence reply to the personite problem to discuss a more general thing, whether the non-existence of Fs entails that Fs don't have moral status. This might seem obviously correct, but in this second I problematize the existence reply.

Begin by what in the context is a warm-up exercise. Suppose you hold an antirealist view on existence, holding that in some way, what exists is up to us. If persons but not personites exist, that is because of how we "carve up the world". If this is your view on existence, you can hardly reasonably appeal to existence facts to back up the claim that objectively, the interests of persons but not of personites should be taken into account in moral reasoning. Given this view, you can be happy about going on to use the existence of persons and non-existence of personites to justify taking persons to have a more distinguished moral status (or to be the only person-like entities with moral status) only if you embrace anti-realism also with respect to moral matters. And if what is sought is not an objective reason to favor persons over personites but only a reason-for-us, the problem may not be so pressing any more: we can then resolve the problem by appeal to, say, how we in fact assign moral status to persons but not to personites. ${ }^{24}$

\footnotetext{
${ }^{24}$ Finding "reasons-for-us" may be more complicated than let on in the main text. A plausible version of a "reasons-for-us" view would appeal to what we would take to be reasons under some ideal circumstances, like when we have all the non-moral information. But then note: while we don't normally take personites into consideration, it could still be that under these ideal circumstances we would take personites to exist.
} 
So set aside this kind of antirealism about existence. Let us instead proceed on the assumption that the truth-values of the propositions expressed by the sentences "persons exist" and "personites exist" are an entirely objective matter, not up to us and our carvings at all.

A central discussion in the metaontology literature concerns the doctrine of quantifier variance $(\mathrm{QV}){ }^{25}$ There are several related doctrines in the literature which the label QV has been used for. But let me here use QV as a label for a specific one of the doctrines involved: the claim that our existence concept is just one among many non-coextensive existence concepts, and no existence concept is metaphysically privileged over all others. ${ }^{26} \mathrm{QV}$ is not in any immediate conflict with realism. QV is compatible with the propositions expressed by sentences like "persons exist" being true or false as an entirely objective matter. It only adds that there are other existence concepts, non-coextensive with the ordinary concept EXISTS, so if "exists*" expresses one of these other concepts, the truth-value of the proposition expressed by "persons exist*" may be different from that of the proposition expressed by "persons exist".

The idea behind QV is that there could be different linguistic communities, using different languages, such that one community uses one existence concept and the other uses a non-coextensive existence concept, and neither of these concepts is privileged over the other.

A different idea, also discussed under the label QV, is that ontological disputes are merely verbal: the disputants do not have a disagreement over anything substantive but are merely using ontological expressions with different meanings. Let me here call this verbalism. Verbalism is different from QV, in the present sense of QV. Verbalism says nothing about metaphysical privilege, or lack thereof. QV says nothing about a dispute being verbal. A verbalist diagnosis of a dispute over the existence of personites, saying that theorists appearing to have a dispute over whether personites exist have a merely verbal dispute, does not have the consequences that QV has.

In the metaontology debate, QV serves as the basis for deflationary claims about the nature and significance of ontological inquiry. (Ontologists like to invest questions about what exists with being somehow deep and fundamental. But what is the interest of figuring out that Ks exist if we could equally well theorize about the world in terms of existence*, and existence is not privileged over existence*?) But my concern here is not with what consequences QV may or may not have for ontological inquiry, but with its consequences in connection with the personite problem. There is an obvious way in which QV, if true, problematizes the existence reply to the personite problem: even if persons exist and personites don't, personites can still exist*, and existence* is no less privileged than existence.

Consider two languages of the sort postulated by QV, employing different existence concepts. Let the languages be variants of English, like English except for

\footnotetext{
${ }^{25}$ QV was introduced, under that name, by Eli Hirsch (see the essays collected in his 2011), but inspired by Putnam's writings. For discussion, see Eklund (forthcoming).

26 This is for example how QV is characterized in Sider (2007).
} 
differences of the kind noted. In $\mathrm{L}_{\text {restr }}$ " "persons exist" is true but "personites exist" is not. In $\mathrm{L}_{\mathrm{lib}}$, both "persons exist" and "personites exist" are true. ("Restr" for restrictive- $\mathrm{L}_{\text {restr }}$ is a language which so to speak uses a more restrictive existence concept. "Lib" for liberal- $\mathrm{L}_{\mathrm{lib}}$ is more liberal.) Correspondingly if other ontological expressions than "exists" are used, and we consider, e.g., "there are personites". While discussion of QV often primarily focuses on what happens with sentences containing "existence" and similar expressions, the friend of QV also typically holds that sentences not containing ontological expressions are also affected, for example because existential quantification is supposed to obey standard rules within the different languages. ${ }^{27}$ In $\mathrm{L}_{\text {restr }}$, "persons feel pain" is true, but "personites feel pain" is not. (The speaker of $\mathrm{L}_{\text {restr }}$ can say, using her language, “Since personites don't exist, personites don't feel pain".) In $\mathrm{L}_{\text {lib }}$, both "persons feel pain" and "personites feel pain" are true. And where "A" is a name for a person and "A-" is a name for a personite, there will be true sentences of the form "A is $F$ " in both $\mathrm{L}_{\text {restr }}$ and $\mathrm{L}_{\text {lib }}$, but there will be true sentences of the form "A- is $F$ "

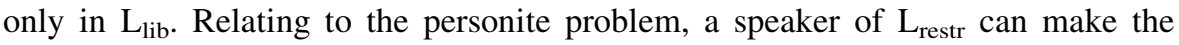
speech "Personites don't exist. Hence they don't feel pleasure/pain, don't have interests, etc. Hence they don't have moral status". But a speaker of $\mathrm{L}_{\text {lib }}$ can make a corresponding speech on the opposite side ("Personites do exist. They do feel pleasure/pain...") in her language, and there is nothing that privileges $\mathrm{L}_{\text {restr }}$ as described over $\mathrm{L}_{\text {lib }}$ as described.

What, for all that has been said, might help get around the personite problem would be the stronger claim that for none of the equally privileged existence concepts is it the case that personites 'exist' in the sense of that concept. Call this the strong non-existence claim. I will get back to the strong non-existence claim below.

\section{Other metaontological views}

QV is itself a controversial doctrine. Even if the truth of QV would problematize some claim, that may not be very significant. Lots of perfectly fine claims are in tension with some controversial view or other.

However, even if QV itself is controversial, the themes brought in via consideration of QV still problematize the existence reply to the personite problem.

\footnotetext{
27 The idea is that none of the languages should function in such a way that, e.g., there are true sentences of the form "__ is F" but no true sentence of the form "there is something which is F". In the main text I only consider what I take to be the most natural route for the friend of QV to take. What about if she takes another route? Suppose that the friend of QV takes the languages in question to only differ when it comes to sentences involving ontological expressions: no variance of any kind when it comes to sentences without such expressions. Then the relevance for the personite problem seems to be lost. For there is no significant variance in sentences about personites having interests, feeling pleasure and pain, etc.: and truths about these matters seem to be sufficient for determining whether personites have moral status. Issues about existence seem only to matter insofar as they are of consequence for such matters, for example because it seems that if personites don't exist then ipso facto they can't have properties like having interests, feeling pleasure and pain, etc.
} 
In this section, I will show that the existence reply is problematic even given other metaontological positions.

In the metaontology literature, perhaps the most important competing view is Ted Sider's ontological realism (OR), according to which there is a metaphysically privileged existence concept (which may or may not be the ordinary existence concept). ${ }^{28} \mathrm{OR}$ as officially characterized is compatible with the view that there is only one existence concept. But given the way Sider tends to discuss OR, Sider's view is that there are different existence concepts but one is metaphysically privileged.

Suppose we adopt Sider's view. In this setting, the natural version of the existence reply is to say that persons exist in the privileged sense but personites do not. But through the introduction of considerations regarding metaphysical privilege, we arrive at something more similar to what I called the second-class reply, which directly concerned metaphysical privilege. And the same question arises as with respect to the second-class reply: what bearing does metaphysical privilege have on the normative questions in the vicinity? To be sure, there are differences: now what is purportedly relevant isn't whether such-and-such personlike entities are privileged, but whether such-and-such a notion of existence is metaphysically privileged. But the question is still what bearing metaphysical privilege has on normative questions.

Relating back to the languages $\mathrm{L}_{\text {restr }}$ and $\mathrm{L}_{\text {lib }}$, Sider's ontological realist does not disagree with the friend of QV over there being languages of the kind described. It is only that he thinks that the existence concept employed by one of these languages may be metaphysically privileged. My point is that this supposed fact does not mean that existence in the metaphysically privileged sense is of greater moral import than existence in some less privileged sense.

It would be different if metaphysical privilege was in part determined by normative considerations. Suppose that, for some reason or other, persons do have moral status and personites don't_ - and that for this very reason the metaphysically privileged existence concept must be such that persons but not personites fall under it. This would get around the problems I have brought up regarding metaphysical privilege. I have said nothing to block this strategy. But notice how dialectically ineffectual it is. The initial thought behind the "personites don't exist!" response was that this was an alternative to responses which more straightforwardly pointed to supposedly morally relevant differences between persons and personites. But given the strategy outlined, the appeal to the non-existence (that is, "non-existence" in the privileged sense of "exists") is dependent upon these more straightforwardly moral considerations.

Both QV and OR as Sider in fact discusses it agree that there are different possible existence concepts. Call this thesis multitude. Given multitude, the existence reply to the personite problem faces problems. Either no existence concept is metaphysically privileged over the others and QV is true, or there is a metaphysically privileged existence concept and OR is true.

${ }^{28}$ Sider $(2009,2011)$. 
What about giving up multitude and instead claim that there is only one possible existence concept? Any friend of multitude grants that there are different possible existence concepts. Perhaps it is this assumption that ought to be rejected. Perhaps there is, in the relevant sense, only one existence concept.

However, I think something just must have gone wrong if we end up here. We have arrived at a point where it seems crucially to matter what the conditions are for a concept, potentially different from our concept EXISTS, to count as an existence concept. But a question "is concept $\mathrm{C}$, which is like our concept ExISTS in some ways and unlike it in others, an existence concept?" smacks of being misguided. In some ways, $\mathrm{C}$ is like our concept ExISTS and in some other ways it is not. Whether to call it an existence concept is a matter of theoretical bookkeeping. How can a significant philosophical issue, like that of what would get around the personite problem, really turn on that? Yet it seems that this is what we run up against. Compare perhaps: suppose that we encounter a concept, \#, that behaves in many ways but not all like our concept of negation. Suppose for example it allows that $\mathrm{P}$ and \#P can be true at the same time, but only when $\mathrm{P}$ is liar-paradoxical; whereas ordinary negation is such that a proposition and its negation can never be true at the same time. Is \# a negation concept? Well, it is not our concept of negation but it behaves like it in many ways. Those are all the relevant facts. Whether to call it a negation concept seems to be just a matter of theoretical bookkeeping.

Maybe if the concept of negation serves a certain useful function that \# does not serve, we can for that reason refuse to call \# a negation concept. But if that is what guides the use of the locution "__ concept", then we here simply encounter the same sorts of issues as were encountered in the discussion of dependence and privilege. If the central function that a concept $\mathrm{C}$ needs to be able to serve in order to count as an existence concept is not directly connected to normative matters one can always ask: why should C's serving that function be taken to mean that something's having moral status is dependent on whether it falls under C? Compare earlier remarks concerning how metaphysical privilege need not translate into anything of normative importance.

It may be useful to return to the earlier example of $\mathrm{L}_{\text {restr }}$ and $\mathrm{L}_{\text {lib. What should }}$ someone who rejects multitude say about the possibility of there being two languages $\mathrm{L}_{\text {restr }}$ and $\mathrm{L}_{\text {lib }}$ as described? She might say that there can be such languages and they can work as described but the "exists" of at least one of these languages fails to express an existence concept. Or, more radically, she might say that there could not even be languages where "exists" works in these different ways, whether or not we decide to call the concepts expressed by these different words "exists" existence concepts or not. What I have said so far about the option of rejecting multitude has implicitly assumed that she takes the first route. Things stand differently if she takes the second route: but I don't see how one could plausibly deny that there could be languages as described. Why could a word "exists" not function as specified? Possible languages are cheap.

The remarks on the rejection of multitude are relevant also to what I called the strong non-existence claim: that QV might be true but personites fall under none of the "best" existence concepts. Also this suggestion crucially relies on what it takes to count as an existence concept, and is problematic for that reason. 
Let me recapitulate the main points of this section. I considered the existence reply to the personite problem and rejected it. The considerations turned on metaontology. I considered different metaontological views-QV, ontological realism, and the rejection of multitude - and noted problems in each case. Call this response to the existence reply the metaontology rebuttal.

\section{The predications reply}

In this section, I will present a reply to the metaontology rebuttal. In the following sections I will discuss responses to this reply in turn.

Here is what I said above, discussing the illustrative case of languages $L_{\text {restr }}$ and $\mathrm{L}_{\text {lib }}$-italics now added:

Relating to the personite problem, a speaker of $\mathrm{L}_{\text {restr }}$ can make the speech "Personites don't exist. Hence they don't feel pleasure/pain, don't have interests, etc. Hence they don't have moral status". But a speaker of $L_{l i b}$ can make a corresponding speech in her language, and there is nothing that privileges the existence concept used in $\mathrm{L}_{\text {restr }}$ over the existence concept used in $\mathrm{L}_{\text {lib }}$.

But in just what sense does the speech in $\mathrm{L}_{\text {lib }}$ "correspond" to that of $\mathrm{L}_{\text {restr }}$ ? The speaker of $\mathrm{L}_{\mathrm{lib}}$ can say "Personites do exist. Hence-given their similarity to persons - they do feel pleasure/pain, do have interests, etc. Hence they do have moral status." Here there is a kind of analogy. But, importantly, it would be at least misleading to represent the speaker of $\mathrm{L}_{\text {restr }}$ as saying that personites don't exist, don't feel pleasure/pain, etc, and at the same time representing the speaker of $\mathrm{L}_{\mathrm{lib}}$ as saying that personites do exist, do feel pleasure/pain, etc. ${ }^{29}$ The reason should be plain. Given the differences in meaning between expressions of $\mathrm{L}_{\text {restr }}$ and expressions of $\mathrm{L}_{\mathrm{lib}}$, we should be careful about assuming that same-sounding sentences of the two languages mean the same. Suppose our language is $\mathrm{L}_{\text {restr }}$. Then we should understand the "personites don't exist" of $\mathrm{L}_{\mathrm{lib}}$ as meaning that personites don't exist*, where "exist*" is our label for the concept of existence employed in $\mathrm{L}_{\text {lib. }}$

Moreover, as stressed in the previous section, the differences in meaning between expressions of $\mathrm{L}_{\text {restr }}$ and $\mathrm{L}_{\text {lib }}$ extend beyond the overtly ontological expressions. ${ }^{30}$ Sentences of the form "A- is F" will likewise differ in meaning, and sentences of the form "personites are F" do too. In fact, speaking $\mathrm{L}_{\text {restr, }}$ I may well say that the

\footnotetext{
29 As discussed in, e.g., Cappelen (2018, ch. 10), the ordinary "saying" locution is liberal in such a way that in ordinary language two sentences can count as saying the same thing even when they are not strictly equivalent. In the text, I use "saying that" in the more strict sense common in philosophical prose, where if two predicates $F$ and $G$ are not coextensive, sentences of the form "_ is F" and "_ is G" do not count as say the same thing.

30 And see footnote 27, regarding the possibility that the differences do not extend beyond the overtly ontological expressions.
} 
relevant sentences of $\mathrm{L}_{\mathrm{lib}}$ are not about personites at all. The predicate "personite" of $\mathrm{L}_{\mathrm{lib}}$ does not mean the same as my own "personite" predicate, that of $\mathrm{L}_{\text {restr }}$, does.

This suggests the following reply to the metaontology rebuttal. We can set aside all questions about how quantifiers and other ontological expressions ("object", "exists") work, and instead focus on relevant kinds of sentences of the form "A- is F", where "A-" purports to refer to a personite, and " $F$ " is some predicate pertaining to moral matters. We can ask: are there some true sentences of this kind? If there are, then personites should count as having moral status; if not, then they do not. And I can use the truth-values of the sentences of my own language as guide. That the corresponding sentences of $\mathrm{L}_{\text {lib }}$ have different truth-values is not relevant: for these sentences are not actually about personites - the name "A-" of $\mathrm{L}_{\text {lib }}$ does not mean the same as name "A-" of $\mathrm{L}_{\text {restr, }}$ " "personite" of $\mathrm{L}_{\text {lib }}$ does not mean the same as "personite" of $\mathrm{L}_{\text {restr }}$.

It does not immediately follow from the fact that some non-ontological expressions differ in meaning between the language that both the names involved and the predicates involved differ in meaning. The most that we can conclude is that some expressions other than overtly ontological ones differ in meaning between the languages in question. There is a step from there to pinning the difference in meaning on particular individual expressions. When " $\mathrm{A}$ - is in pain" in $\mathrm{L}_{\text {restr }}$ differs in meaning from "A- is in pain" of $\mathrm{L}_{\mathrm{lib}}$, we can pin the meaning difference on either the name or the predicate or both, but it is not immediately clear what to say. But instead of pausing on complications there, let me just assume, for argument's sake, that we indeed have good reason to think that both "A-" and "personite" differ in meaning between the languages. (I will later focus on other complications regarding this reply to the metaontology rebuttal.)

Call the suggested reply the predications reply to the metaontology rebuttal. Whereas the metaontology rebuttal focused on different views on existence concepts, the predications reply stresses that we can get around those complications by focusing on possible true predications. ${ }^{31}$ Are there possible true sentences (of a relevant kind) where the subject purports to refer to a personite? If yes, then personites have moral status; if not, then no. The sentences we are concerned with do not contain expressions expressing existence concepts.

Let me emphasize the idea behind the predications reply. If our language is $\mathrm{L}_{\text {restr }}$, then not only is it the case that "personites don't exist" comes out true in our language, but what is more, no relevant sentence of our language like "A- is in pain" or "A- has interests" comes out true. And even if same-sounding sentences of another language do come out true, the subject terms of those sentences differ in meaning from the subject terms of my sentences in such a way that the subject terms of those sentences don't purport to refer to personites. So nothing relevant can be truly predicated of personites, in any language. But then personites don't have moral

\footnotetext{
31 Possible, because the issue does not hinge on what languages are actually used. The "possible" must be understood in the right way. One way there can be "possible true predications" involving Fs is if Fs don't exist in the actual world but in another possible world. Such possibilities are beside the point. The relevant variability concerns representations. Keeping the non-representational world as it is, is it possible that there are true predications where the singular term purports to refer to a personite?
} 
status. This purports to be a more sophisticated version of the existence reply. Where the original existence reply focused on existence, this version focuses on true predications. $^{32}$ The idea is that one might in this way evade issues in metaontology, having to do with existence.

\section{Symmetry}

If the predications reply works, then one can after all uphold the seemingly eminently reasonable claim that if Fs don't exist, then Fs don't have moral status. But in this section and the next, I will bring up two serious concerns regarding the predications reply.

A first concern about the predications reply appeals to the symmetry of the situation.

When, above, I illustrated the predications reply it was just stipulated that we were speakers of $\mathrm{L}_{\text {restr }}$. It may be thought that we are plausibly speakers of $\mathrm{L}_{\text {restr }}$ rather than $\mathrm{L}_{\text {lib. }}$ But even if that is so, $\mathrm{L}_{\text {lib }}$ is a possible language to speak. We could have used $\mathrm{L}_{\text {lib }}$. Suppose we are in fact speakers of $\mathrm{L}_{\mathrm{lib}}$, and we consider the personite problem. Suppose further that no more straightforwardly normative reply to the personites problem is workable. Then we as speakers of $\mathrm{L}_{\mathrm{lib}}$ should, it appears, reason our way to the conclusion "personites have moral status". What is more, we should change our practices in light of this, taking the interests of personites into account.

But now compare two communities, one speaking $\mathrm{L}_{\text {restr }}$ and one speaking $\mathrm{L}_{\text {lib }}$. We have seen how speakers of $\mathrm{L}_{\text {restr }}$ can convince themselves that (as they would put it) "personites don't have moral status" and how speakers of $\mathrm{L}_{\text {lib }}$ can convince themselves that (as they would put it) "personites have moral status". There is a

\footnotetext{
32 There are other possible concerns about the metaontology rebuttal besides those that come up in the predications reply. There is no space here to discuss them fully. Let me briefly mention these concerns and how I reply.

(1) Doesn't the metaontology rebuttal generalize in problematic ways? For all sorts of weird entities can be such that they exist in some sense of "exists". Consider fictional entities. Consider our "inverses", person-like entities coinciding with persons but having interests that are the opposite of the persons they coincide with. Should we then say that fictional entities and inverses have the same status as people?Here I think that in the cases brought up, there are relevant differences between personites and the entities postulated, in such a case that for independent reasons the entities postulated don't raise a moral problem anywhere near as serious as the personite problem. Regardless of whether personites exist, the hypothesis that they do does not conflict with our best hypotheses about what stuff there is, and about what exists where at a more fundamental level. The hypothesis that fictional entities, conceived of as concreta, and inverses exist do conflict with these hypotheses.

(2) The metaontology rebuttal focuses on existence concepts and cognate concepts. But once we note the general strategy behind it-focusing on concepts that are in some sense alternatives to our ordinary concepts-we can see that the general strategy generalizes wildly. But then why the focus on existence?-I agree that the general strategy generalizes wildly. In Eklund (2017), I discuss how related problems arise for normative concepts generally. Later in this paper, I will discuss how these issues arise regarding truth. In a way, there is then no reason to focus specifically on existence. But the application to existence has interesting consequences in the case of the personite problem.
} 
sense in which the speakers of $\mathrm{L}_{\text {restr }}$ and speakers of $\mathrm{L}_{\text {lib }}$ speak past each other when using these sentences: the propositions that these sentences express may be compatible. But there still is a practical conflict between the communities: when one community considers the practices of the other, it will seem that the others are making moral mistakes. And even if the communities speak past each other when talking about personites there may be other ways for them to express a disagreement, focusing on sentences without anything like personite talk. They may have a disagreement over the truth of certain sentences of the form "one ought to $\phi$ ", and mean the same thing by such sentences. To the extent that the mistake on the other side seems egregious (imagine the $\mathrm{L}_{\text {lib }}$ speakers reasoning: "Look how

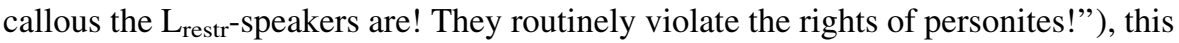
seems to be an important moral matter.

Moreover, nothing in the predications reply gives us any purchase on the idea that it is one community rather than the other that is making a moral mistake. The speakers of $\mathrm{L}_{\text {restr }}$ can reason that the speakers of $\mathrm{L}_{\text {lib }}$ are making a mistake; but the speakers of $\mathrm{L}_{\text {lib }}$ can equally reason this way about speakers of $\mathrm{L}_{\text {restr. }}{ }^{33}$

\section{Revenge}

I guess I believe that the foregoing problem is problem enough with the predications reply. But there is another problem as well. Bringing it up may in some sense be overkill, but the themes brought up are of considerable interest in their own right.

Suppose we wish to accept the strategy behind the predications reply, and take the question of whether there can be true atomic sentences of a relevant kind whose subject terms purport to refer to personites to be pivotal. In particular, if there are no such true sentences, then personites lack moral status.

Then the problem arises: can one not problematize the notion of being the subject of true predications in the same way that QV and other metaontological doctrines problematize the notion of existence? In the spirit of QV, one can suggest that there are different, non-coextensive truth concepts and none of them is better than the others. This is a doctrine of truth variance (TV). Or what about the view, analogous to Sider's ontological realism, that there are different, non-coextensive truth concepts but one is privileged over the others? (This might be called alethic realism (AR), by analogy with "ontological realism".)

\footnotetext{
33 In the main text I present the problem as one of symmetry. And what I say in the text is bad enough for the predications reply. But there is a possible way to develop a further argument against the predications reply. Suppose my language is $\mathrm{L}_{\text {restr. }}$ I can reason, speaking my language, that personites don't exist. And I can reason that although another language, $\mathrm{L}_{\mathrm{lib}}$, contains true sentences "personites exist", "A- is a personite" and "A- is suffering", these sentences don't mean what they do in my language. But still: if "A-" is a singular term of $\mathrm{L}_{\mathrm{lib}}$ occurring in true sentences of that language, I can arguably conclude that "A-“ refers to something. (This reasoning parallels a well-known but controversial argument against QV found in the literature. For discussion see e.g. Eklund (2007, 2009, forthcoming), Hawthorne (2006), Hirsch and Warren (forthcoming), and Sider (2007, 2011, ch. 9).) Call the type of thing that A- refers to a K. So I must say that Ks exist. And now-even if I have concluded that personites don't exist, must I not say that even if $\mathrm{Ks} \neq$ personites, Ks are sufficiently person-like that they have moral status?
} 
What might these different truth concepts be? One way to arrive at TV and AR doctrines is to conceive of the truth concepts as corresponding to different traditional theories of truth: there are (e.g.) correspondence concepts, coherence concepts, deflationary concepts, and various broadly verificationist and pragmatist concepts. Another way to arrive at TV and AR doctrines is to conceive of different truth concepts as differing extensionally, in a way analogous to how the existence concepts of $\mathrm{L}_{\text {restr }}$ and $\mathrm{L}_{\text {lib }}$ differ extensionally. One and the same sentence "personites exist", with a given meaning, can be true in the sense of one truth concept and untrue in another. It is this latter kind of situation which is most directly relevant to the personite problem.

In just what sense would the different concepts be correctly regarded as truth concepts? Well, truth functions as something like a norm of acceptance or belief. We can imagine different communities using different truth-like norms for that purpose. One community employs the norm: accept that $\mathrm{P}$ iff $\mathrm{P}$ is true1. Another community employs the norm: accept that $\mathrm{P}$ iff $\mathrm{P}$ is true2. ${ }^{34}$

Given either TV or AR, true predications do not present a comfortable resting point. True in what sense? Suppose our truth concept is truth ${ }_{\text {restr }}$, and that there are

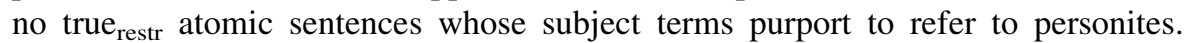
What does this matter if there's an equally good truth concept, truth $_{\text {lib }}$, such that there are some true $_{l i b}$ atomic sentences whose subject terms purport to refer to personites? And if one or other of these truth concepts is metaphysically privileged over the other, why think this matters regarding the moral matters under discussion?

If the problem was just that there are different possible words "true" meaning different things, then one could maybe get around the problem by shifting the focus from contexts where this word occurs to contexts where it does not. Recall how the strategy of the predications reply was to shift the focus away from the use of expressions expressing different existence concepts. But the issue raised concerns the status of sentences that do not themselves contain alethic vocabulary. If say, "Ais suffering" (where "A-" purports to name a personite) is true 2 but not true1, then what should one's attitude be toward (the proposition expressed by) this sentenceshould one accept it?

It is natural to think that there is a close link of some sort between acceptance and truth: accepting that $\mathrm{P}$ is to take $\mathrm{P}$ to be true. But even if there is such a link, appeal to it does not immediately help avoid the difficulties introduced by TV and AR. Even if there is this link between acceptance and truth, it can be held that if there are these different truth concepts then there are, correspondingly, different acceptance concepts. Acceptance ${ }_{\text {restr }}$ that $\mathrm{P}$ is linked to truth ${ }_{\text {restr }}$, acceptance lib $_{\text {ib }}$ that $\mathrm{P}$ is linked to truth $_{\text {lib }}$, etc. What might possibly help is if there is, in some sense, only one notion of acceptance, and the one genuine truth notion is whichever notion is related in the right way to this notion of acceptance.

With regard to the personite problem, TV and AR raise the same sorts of problems as QV and OR initially seemed to do. When we ask whether personites

\footnotetext{
34 Some may be skeptical of talk of "norms governing acceptance". Is it clear that acceptance is an attitude governed by norms? But the point can also be put in less normative terms, in terms of what the people in question seek to do, or are disposed to do.
} 
can be subjects of true predications, what notion of truth are we and should we be employing? And while we might have thought that we can sidestep questions about existence by talking directly about true predication, the idea that we can sidestep the questions we now face by turning to something different still does not seem at all promising. To get around supposed issues regarding the quantifier we could retreat to speaking of true predications. But what could we possibly retreat to when similar issues are raised regarding true predication itself?

One natural concern regarding the problem of different truth concepts serving as different norms of acceptance is that the assumption that there are such concepts is incoherent. Suppose we try to imagine a community such that their truth concept differs from us in such a way that their truth concept applies to different things from what our truth concept applies to, where these concepts are the different communities' truth concepts in the sense that the communities use different norms of acceptance. Why should we take this case to be one where the communities use different truth concepts rather than one where the communities make judgments about different contents? Start with a toy example. Suppose we try to imagine a community whose norms of acceptance is to accept something just in case it is false in our sense. Why should we not understand this community as simply meaning not $P$ by "P", and vice versa? This is of course an extreme case, but suppose some community uses some notion of provability as their acceptance norm. ${ }^{35}$ By their norms they ought to assertively utter " $P$ " in exactly the cases where we by our norms ought to assertively utter " $\mathrm{P}$ is provable". Why should we take them to mean that $\mathrm{P}$ by "P" instead of meaning by " $\mathrm{P}$ " that it is provable that $\mathrm{P}$ ?

I have elsewhere put forward this kind of argument myself. ${ }^{36}$ But even assuming that the argument is correct as far it goes, this kind of argument has serious limitations. Compare Hilary Putnam's (1981) famous reply to skepticism: the brainin-a-vat won't in fact be deluded when it thinks "I am not a brain in a vat", for the right (causal) theory of reference will yield that what it means by "brain" and "vat" won't be brain and vat, respectively. Many theorists have noted the significant limitations of this reply: for example, an only recently envatted brain will still be deluded, for the brain will still mean brain and vat by "brain" and "vat". ${ }^{37}$ The argument just mentioned arguably has corresponding limitations. The friend of the view that a community might switch from one truth norm to another can respond by saying that if the community has only recently switched from one truth norm to another, the expressions used plausibly still retain their old meanings, given plausible metasemantic views on how it is determined what meanings expressions have. The meanings of the expressions remain determined by past uses of these expressions in such a way that the expressions have the same meaning as before even after the recent shift in norms.

\footnotetext{
35 The example of provability is not random: in discussions of intuitionism and verificationism it has been suggested that truth can be equated with provability, suitably understood.

36 See Eklund (2012, 2015). My immediate target was Stich (1990), who considers alternative truth concepts.

37 Some early discussions where this is noted are Smith (1984) and Brueckner (1986).
} 


\section{Conclusion}

The structure of the discussion has been complex. Let me close by recapitulating. I started by describing the personite problem, and noted that a quick way of dealing with the problem is to simply say that personites just don't exist. Then I turned to metaontology, and noted hat no matter which metaontological stance we adopt, the strategy behind the existence reply seems flawed. Having done that, I noted that a reply to the personite problem in the spirit of the existence reply could still be salvaged despite this: one that focuses on true predications instead of on existence. But this reply, too, is problematic, for example because problems analogous to those raised regarding existence can be raised regarding truth.

Where does this leave us when it comes to the personite problem? Only one possible reply to the personite problem has been investigated. For all I have said, other replies could be workable. My aim has just been to raise problems, of a metacharacter, with the existence reply. The bigger aim behind this has been to show the relevance of issues in metaontology, and other issues with a similar meta-character, to issues in ethics.

Acknowledgements Many thanks to Nils Franzén, Katharina Felka, Olle Risberg, and audiences at the Ontoformat Metaphysical Seminar at the University of Milan, the workshop Deflationism in Metaphysics at the University of Vienna, and the 10th Arché Graduate Conference at the University of St Andrews.

Open Access This article is distributed under the terms of the Creative Commons Attribution 4.0 International License (http://creativecommons.org/licenses/by/4.0/), which permits unrestricted use, distribution, and reproduction in any medium, provided you give appropriate credit to the original author(s) and the source, provide a link to the Creative Commons license, and indicate if changes were made.

Funding Funding was provided by Riksbankens Jubileumsfond (Grant No. P14-0268:1).

\section{References}

Brueckner, A. (1986). Brains in a vat. Journal of Philosophy, 83, 148-167.

Cappelen, H. (2018). Fixing language. Oxford: Oxford University Press.

Chalmers, D., Manley, D., \& Wasserman, R. (Eds.). (2009). Metametaphysics. Oxford: Oxford University Press.

Dougherty, T. (2014). Vague value. Philosophy and Phenomenological Research, 89, 352-372.

Dunaway, B. (2016). Expressivism and normative metaphysics. Oxford Studies in Metaphysics, 11, 241-264.

Dunaway, B., \& McPherson, T. (2016). Reference magnetism as a solution to the moral twin earth problem. Ergo, 3, 639-679.

Eklund, M. (2007). The picture of reality as an amorphous lump. In T. Sider, J. Hawthorne, \& D. Zimmerman (Eds.), Contemporary debates in metaphysics. Oxford: Blackwell.

Eklund, M. (2009). Carnap and ontological pluralism. In Chalmers, Manley and Wasserman (Eds.) (2009) (pp. 382-396).

Eklund, M. (2012). The multitude view on logic. In G. Restall \& G. Russell (Eds.), New waves in philosophical logic (pp. 217-240). London: Palgrave Macmillan.

Eklund, M. (2015). Intuitions, conceptual engineering, and conceptual fixed points. In C. Daly (Ed.), The Palgrave handbook of philosophical methods (pp. 363-385). London: Palgrave Macmillan.

Eklund, M. (2017). Choosing normative concepts. Oxford: Oxford University Press. 
Eklund, M. (forthcoming). Collapse and the varieties of quantifier variance.

Hawthorne, J. (2006). Plenitude, convention and ontology. Metaphysical essays (pp. 53-70). Oxford: Oxford University Press.

Hirsch, E. (2011). Quantifier variance and realism. Oxford: Oxford University Press.

Hirsch, E., \& Warren, J. (forthcoming). Quantifier variance and the demand for a semantics. Philosophy and Phenomenological Research.

Johnston, M. (1997). Human concerns without superlative selves. In J. Dancy (Ed.), Reading parfit (pp. 149-179). London: Blackwell.

Johnston, M. (2016a). The personite problem: Should practical reason be tabled? Nô̂s, 51, 617-644.

Johnston, M. (2016b). Personites, maximality and ontological trash. Philosophical Perspectives, 30, $198-228$.

Olson, E. (2010). Ethics and the generous ontology. Theoretical Medicine and Bioethics, 31, $259-270$.

Parfit, D. (1984). Reasons and persons. Oxford: Oxford University Press.

Putnam, H. (1981). Reason, truth and history. Cambridge: Cambridge University Press.

Schoenfield, M. (2016). Moral vagueness is ontic vagueness. Ethics, 126, 257-282.

Setiya, K. (2015). Selfish reasons. Ergo, 2, 445-472.

Sider, T. (2007). Neo-fregeanism and quantifier variance. Proceedings of the Aristotelian Society, 81, 201-232.

Sider, T. (2009). Ontological realism. In Chalmers, Manley and Wasserman (Eds.) (2009) (pp. 384-423).

Sider, T. (2011). Writing the book of the world. Oxford: Oxford University Press.

Smith, P. (1984). Could we be brains in a vat? Canadian Journal of Philosophy, 14, 115-123.

Stich, S. (1990). The fragmentation of reason. Cambridge: MIT Press.

Thomasson, A. (2015). Ontology made easy. Oxford: Oxford University Press.

Wasserman, R. (2012). Personal identity, indeterminacy, and obligation. In G. Gasser \& M. Stefan (Eds.), Personal identity: Simple or complex?. Cambridge: Cambridge University Press.

Whiting, J. (1986). Friends and future selves. Philosophical Review, 95, 547-580.

Publisher's Note Springer Nature remains neutral with regard to jurisdictional claims in published maps and institutional affiliations. 